\title{
IOGURTE PROBIÓTICO COM POLPA DE FRUTAS VERMELHAS: CARACTERIZAÇÃO FÍSICO QUÍMICA E MICROBIOLÓGICA, ACEITABILIDADE SENSORIAL E VIABILIDADE DOS PROBIÓTICOS
}

\author{
Probiotic yogurt with red fruit pulp: physical chemical \\ and microbiological characterization, sensory \\ acceptability and probiotics viability
}

Darlila Aparecida Gallina ${ }^{1^{*}}$, Rita Cássia S. Celeste Ormenese ${ }^{2}$, Aline Oliveira Garcia ${ }^{2}$

\begin{abstract}
RESUMO
Este trabalho teve como objetivo elaborar um iogurte probiótico com polpa de frutas vermelhas $(n=3)$ e avaliar a qualidade microbiológica, a composição físico-química, a viabilidade dos probióticos, a aceitação sensorial e intenção de compra, bem como verificar a viabilidade da cultura probiótica e características físico-químicas ( $\mathrm{pH}$, acidez titulável e sinérese) ao longo de 30 dias de estocagem refrigerada. O iogurte apresentou qualidade higiênico sanitária apropriada e composição (média) de: $\mathrm{pH}$ de 4,76; acidez titulável de 0,81 g ácido láctico \%; extrato seco total de 17,67\%; gordura total de 0,22\%; proteína total de 3,51\%; cinzas de $1,05 \%$ e carboidratos totais de $12,90 \%$. O probiótico Howaru Bifido HN 019 manteve-se viável, em torno de $8 \log$ UFC. $\mathrm{mL}^{-1}$ durante os 30 dias de estocagem, em nível considerado terapêutico. O produto obteve mais de $75 \%$ de aceitação para os atributos avaliados, destacando-se a aparência, o sabor e a consistência que obtiveram avaliações médias entre "gostei muito" e "gostei", sendo que 53,3\% dos consumidores demonstraram atitude positiva quanto à intenção de compra.

Palavras-chave: Bifidobacterium spp.; viabilidade; microbiologia; análise sensorial; leite fermentado; polpa de frutas.

1 Instituto de Tecnologia de Alimentos (ITAL), Centro de Tecnologia de Laticínios (TECNOLAT), Av. Brasil, 2880, Jardim Brasil, 13070-178, Campinas, SP, Brasil. E-mail: darlila@ital.sp.gov.br

2 Instituto de Tecnologia de Alimentos (ITAL), Centro de ciência e qualidade de alimentos (CCQA), Campinas, SP, Brasil.

* Autor para correspondência.
\end{abstract}

Recebido / Received: 03/07/2018

Aprovado / Approved: 05/02/2019 


\begin{abstract}
The objective of this study was to elaborate a probiotic yogurt with red fruit pulp $(n=3)$ and to evaluate its microbiological quality, physicochemical composition, probiotic viability, sensory acceptance, and purchase intention. The viability of the probiotic culture and the physicochemical characteristics $(\mathrm{pH}$, titratable acidity and syneresis) were evaluated for 30 days of refrigerated storage. The yogurt showed appropriate sanitary hygienic quality and composition (average) of: $\mathrm{pH}$ of 4.76; titratable acidity of $0.81 \%$ lactic acid; total dry matter of $17.67 \%$; total lipids of $0.22 \%$; total protein of $3.51 \% ; 1.05 \%$ ash and total carbohydrate of $12.90 \%$. The probiotic Howaru Bifido HN 019 remained viable, around $8 \log$ CFU.mL $L^{-1}$ for 30 days of storage and in levels considered therapeutic. The product obtained more than $75 \%$ acceptance for the evaluated attributes, highlighting the appearance, taste, and consistency that obtained the means of proof between "liked very much" and "liked", and $53.3 \%$ of consumers demonstrated a positive attitude towards the purchase intention.
\end{abstract}

Keywords: Bifidobacterium spp; viability; microbiology; sensory evaluation; fermented milk; fruit pulp.

\section{INTRODUÇÃO}

Alimentos funcionais podem ser definidos como alimentos com benefícios para saúde além do seu valor nutricional básico. Em particular, os probióticos são uma das categorias mais lucrativas dentro do mercado de alimentos funcionais. Produtos lácteos são o veículo mais usual para conduzir probióticos para os consumidores, sendo o iogurte e os leites fermentados os produtos mais comuns (OLIVEIRA et al., 2017).

Probióticos são definidos como microrganismos vivos os quais quando administrados em quantidades adequadas conferem benefícios à saúde do hospedeiro (FAO/ WHO, 2001). Contudo, para conferir benefícios à saúde, as bactérias probióticas devem chegar ao intestino vivas e em quantidades suficientes, em torno de 6 a $7 \mathrm{log} \mathrm{UFC} / \mathrm{g}$ (KUMAR; KUMAR, 2016). De acordo com Kailasapathy et al. (2008) níveis de ingestão diária recomendada de probióticos de pelo menos $10^{7}$ e $10^{8} \mathrm{UFC} / g$ são recomendados para conferir benefícios à saúde. A Federação Internacional de Laticínios (IDF) reco- menda uma quantidade mínima de $10^{7}$ UFC por $\mathrm{g}$ de produto consumido (LOURENSHATTINGH; VILJOEN, 2001; KAUR et al., 2014). A eficácia da adição de bactérias probióticas depende do nível de inóculo e sua viabilidade deve ser mantida através da estocagem e a vida de prateleira do produto, e elas devem sobreviver ao ambiente intestinal. No entanto, a viabilidade dos probióticos na matriz alimentar está relacionada a diferentes fatores, como: $\mathrm{pH}$, ácidos orgânicos, temperatura de armazenamento, níveis de oxigênio, presença de microrganismos e inibidores (KAILASAPATHY et al., 2008).

O emprego de bactérias probióticas em produtos lácteos fermentados tem sido amplamente estudado devido às dificuldades de manutenção da viabilidade destes microrganismos ao longo da estocagem refrigerada. Alimentos probióticos devem conter linhagens específicas de microrganismos probióticos e manter um nível apropriado de células viáveis durante o armazenamento do produto, sem interferir no sabor e textura (GALLINA et al., 2012).

O iogurte é um alimento convencional 
conhecido por suas propriedades terapêuticas, nutricionais e sensoriais (GONZALEZ et. al., 2011), sendo o leite fermentado mais conhecido e consumido no Brasil. É definido como o produto obtido pela fermentação lática através da ação do Lactobacillus delbrueckii subsp. bulgaricus e Streptococcus thermophilus sobre o leite integral, desnatado ou padronizado, aos quais podem acompanhar outras bactérias ácido-lácticas (BRASIL, 2007). Ele pode ser feito a partir de leite com alto teor de sólidos, uma cultura láctica e açúcar e pode ser enriquecido com leite em pó, proteínas, vitaminas, minerais ou frutas (ALMEIDA et al., 2008).

Nos últimos anos, iogurtes têm sido reformulados para incluírem estirpes de $L$. acidophilus e espécies de Bifidobacterium em adição aos microrganismos convencionais do iogurte. O bio-iogurte é um iogurte que contém microrganismos probióticos vivos, cuja presença pode proporcionar a alegação de efeitos benéficos para a saúde, sendo um veículo potencial pelo qual os consumidores podem tomar células probióticas (LOURENSHATTINGH; VILJOEN, 2001).

Verifica-se uma tendência em fortificar produtos lácteos com frutas, no intuito de melhorar o valor nutricional e sensorial (KAILASAPATHY et al., 2008). Frutas e vegetais são ricos em compostos bioativos, como vitaminas, compostos antioxidantes e fibras (MELO et al., 2008). Novos produtos e matérias-primas para aplicação de probióticos são a principal área de pesquisa e desenvolvimento para o mercado de alimentos funcionais. As inovações tecnológicas atuais incluem a busca de soluções para os problemas de estabilidade e viabilidade de probióticos em novas matrizes alimentares, como frutas, cereais e outros vegetais (FARNWORTH et al., 2007).

$\mathrm{O}$ iogurte é bem reconhecido como um produto saudável, e espera-se que seu consumo continue crescendo de acordo com as tendências de alimentação saudável. O mercado de iogurtes também é caracterizado por inovações em formulações que ajudam a trazer novos consumidores para este mercado (MACBEAN, 2010). Desta forma, pesquisas são importantes no desenvolvimento de novos alimentos probióticos, visando aumentar o número de produtos com funcionalidade e oferecer novas opções aos consumidores (GRANATO et al., 2010).

O presente trabalho teve como objetivos avaliar a incorporação e manutenção de probióticos em iogurte com polpa de frutas, através de análises físico-químicas, microbiológicas e sensorial, bem como acompanhar as alterações do produto durante a estocagem refrigerada.

\section{MATERIAL E MÉTODOS}

\section{Culturas starter e probiótica}

$\mathrm{Na}$ elaboração do iogurte foram empregadas as culturas comerciais: starter de iogurte ( $S$. thermophilus e L. delbrueckii subsp. bulgaricus - YO-MIX 863 LYO, 500 DCU, Danisco) e probiótica (Bifidobacterium animalis subsp. lactis - HOWARU BIFIDO HN 019, Danisco). A ativação das culturas liofilizadas foi realizada de acordo com as instruções do fabricante. As culturas foram aliquotadas e estocadas a $-22{ }^{\circ} \mathrm{C}$ para posterior uso.

\section{Elaboração do Iogurte probiótico com polpa de frutas vermelhas $(n=3)$}

$\mathrm{Na}$ elaboração do iogurte foram empregados: leite em pó desnatado Molico (Nestlé), polpa de frutas vermelhas (morango, framboesa, amora) pasteurizada (De Marchi), sacarose (açúcar União) e sorbato de potássio (Clariant).

O leite em pó desnatado foi reconstituído $(14 \%)$ e adicionado de $10 \%$ de sacarose. 
Esta mistura foi tratada termicamente a $85^{\circ} \mathrm{C}$ por 20 a 30 minutos em banho termostizado, resfriada $\left(44{ }^{\circ} \mathrm{C}\right)$, adicionada de $0,6 \%$ da cultura termofílica (Yo-mix 863 LYO) e $2 \%$ da cultura probiótica ativada (Howaru Bifido HN 019). A fermentação foi conduzida até $\mathrm{pH}$ $4,7 \pm 0,1$. Ao fim da fermentação, o iogurte foi resfriado a $20-25{ }^{\circ} \mathrm{C}$ e então adicionado de polpa de frutas vermelhas descongelada (18\%) e $0,03 \%$ de sorbato de potássio em condições assépticas (fluxo laminar). As amostras foram estocadas em câmara fria a $8 \pm 2{ }^{\circ} \mathrm{C}$.

\section{Avaliações físico-químicas}

A polpa de frutas vermelhas $(n=3)$ foi avaliada quanto ao $\mathrm{pH}$, acidez titulável (IAL, 2008) e teor de sólidos solúveis totais ( ${ }^{\circ}$ Brix).

O iogurte probiótico foi elaborado em três repetições e avaliado após um dia de fabricação, quanto a composição físico química (pH, acidez titulável, extrato seco total, lipídios totais, proteína total, cinzas, carboidratos totais) e a sinérese espontânea. Com 10, 20 e 30 dias de estocagem foram avaliadas a taxa de dessoragem (sinérese), $\mathrm{pH}$ e acidez titulável.

$\mathrm{O} \mathrm{pH}$ dos iogurtes foi mensurado com pHmetro digital (Micronal B-375). A acidez titulável foi determinada por titulação com solução de hidróxido de sódio $0,1 \mathrm{M}$ até $\mathrm{pH}$ 8,3 (IAL, 2008), com resultado expresso em g de ácido láctico por $100 \mathrm{~g}$ de produto.

O extrato seco total foi determinado estufa com ventilação forçada à temperatura de $100 \pm 2{ }^{\circ} \mathrm{C}$ (BRASIL, 2006) e o resíduo mineral fixo ou teor de cinzas foi obtido através da eliminação da matéria orgânica em mufla à temperatura de $550{ }^{\circ} \mathrm{C}$ (HORWITZ, 2000).

O teor de lipídios ou gorduras totais foi determinado pelo método de Roese-Gottlieb, com a extração da gordura gravimetricamente através de éter etílico-éter de petróleo (BRASIL, 2006).
O nitrogênio total foi determinado pelo método oficial de Kjeldahl, segundo o International Dairy Federation (1993) e o teor de proteína total foi calculado multiplicando-se o conteúdo de nitrogênio total por 6,38.

Para determinar a sinérese, alíquotas de $10 \mathrm{~mL}$ foram estocadas a $8 \pm 2{ }^{\circ} \mathrm{C}$ em tubos de ensaio estéreis de fundo cônico (tipo Falcon: 13 x 1,7 cm) estéreis, realizando-se a medida da dessoragem ou separação do soro na superfície do produto, em centímetros (SILVA et al., 2010).

O teor de carboidratos totais foi determinado por diferença de acordo com a fórmula:

$$
\begin{aligned}
& \text { Carboidratos totais }=[100-(\% \text { umidade } \\
& +\% \text { cinzas }+\% \text { proteína }+\% \text { gordura })]
\end{aligned}
$$

\section{Avaliações microbiológicas}

Os iogurtes $(\mathrm{n}=3)$ foram avaliados após um dia de fabricação, quanto a qualida- de higiênico-sanitária por meio de análises microbiológicas (coliformes a 30 e $45^{\circ} \mathrm{C}$; bolores e leveduras). Verificou-se a viabilidade da cultura probiótica (bifidobactérias) com $1,10,20$ e 30 dias.

A amostragem foi realizada de forma asséptica (câmara de fluxo laminar) e alíquotas de $1 \mathrm{~mL}$ das amostras foram transferidas para tubos com água peptonada estéril $0,1 \%$ para análise.

Os microrganismos do gênero Bifidobacterium spp. foram quantificados em ágar MRS suplementado com cloreto de lítio $(0,1 \%)$, L-cisteína $(0,05 \%)$ e dicloxacilina (0,5 mg/L), com incubação a $37 \pm 1{ }^{\circ} \mathrm{C}$ por $72 \mathrm{~h}$, de acordo com a metodologia descrita no boletim técnico P-12 da Chr-Hansen, com adaptações segundo o IDF (2007). Utilizou-se o plaqueamento por profundidade e incubação em anaerobiose.

As contagens de coliformes a 30 e $45^{\circ} \mathrm{C}$ foram determinadas pelo método do número 
mais provável (NMP), utilizando caldo lauril sulfato triptose (LST), como teste presuntivo, com incubação a $30 \pm 1{ }^{\circ} \mathrm{C}$, por $24 \pm 2$ horas (ISO 4831, 2006). Para confirmação da presença de coliformes, alíquotas de tubos de LST com crescimento microbiano e produção de gás foram transferidas para tubos de caldo verde brilhante $2 \%$ (VB, Difco) e caldo Escherichia coli (EC, Difco). Os tubos de VB foram incubados a $30 \pm 1{ }^{\circ} \mathrm{C}$, por $24 \pm 2 \mathrm{~h}$, para confirmar a presença de coliformes a $30{ }^{\circ} \mathrm{C}$ e os tubos de EC foram incubados por até $48 \pm 2$ horas à $44 \pm 1{ }^{\circ} \mathrm{C}$, para a confirmação da presença de coliformes termotolerantes (ISO 7251, 2005).

Os bolores e leveduras foram enumerados empregando-se o ágar dicloran rosa bengala cloranfenicol (DRBC), com incubação por 5 dias a $25 \pm 1{ }^{\circ} \mathrm{C}$, segundo a metodologia descrita por Frank; Yousef (2004).

\section{Avaliação Sensorial - Teste de aceitabili- dade e Intenção de compra}

Após 10 dias de fabricação, amostras de iogurte probiótico com polpa de frutas vermelhas foram submetidas à análise sensorial por um grupo de 60 consumidores de iogurte de frutas sem restrições quanto à idade, ao sexo e à classe social. Além das questões relacionadas à avaliação do produto, os consumidores responderam a questões sobre hábitos de consumo de iogurte e características pessoais relacionadas à idade $\mathrm{e}$ definição de classe social segundo o critério de classificação econômica Brasil 2014 (ABEP, 2014).

As amostras foram avaliadas quanto à aceitabilidade de modo geral e em particular da aparência, da consistência e do sabor por meio de escalas hedônicas de 9 pontos $(9=$ gostei muitíssimo, 5 = não gostei nem desgostei e 1 = desgostei muitíssimo), quanto à cor, consistência, sabor de frutas vermelhas, acidez e doçura por meio de escala do ideal de 7 pontos $(7=$ muito mais escura/ sabor de frutas vermelhas muito mais intenso/ ácida/ doce/ consistente do que eu gosto, $4=$ do jeito que eu gosto e 1 = muito mais clara, sabor de frutas vermelhas muito menos intenso/ ácida/ doce/ consistente do que eu gosto). Além das questões relacionadas à avaliação dos produtos, os consumidores responderam a questão sobre a intenção de compra $(5=$ certamente compraria, 3 = talvez comprasse/talvez não comprasse e 1 = certamente não compraria) (MEILGAARD et al., 2006).

As amostras foram apresentadas na temperatura de 5 a $10{ }^{\circ} \mathrm{C}$ em copos descartáveis de $50 \mathrm{~mL}$ com código de três números aleatórios, sendo oferecida água mineral natural visando limpar o palato. O teste foi conduzido em cabines individuais com iluminação de lâmpadas fluorescentes e equipadas com o sistema computadorizado Compusense Five versão 5.4 para coleta e análise dos dados.

\section{Análise estatística}

Os fatores $\mathrm{pH}$, acidez titulável, sinérese e contagem de probióticos foram avaliados ao longo do período de 30 dias de estocagem refrigerada. O teste de análise de variância (ANOVA) seguido pelo teste Tukey, foram empregados para avaliar o efeito do tempo de armazenamento sobre as amostras. Os dados foram analisados através do software Minitab, versão 16.1.1.

\section{RESULTADOS E DISCUSSÃO}

\section{Composição físico-química}

A acidez titulável média $(n=3)$ da polpa de frutas vermelhas (morango, amora, framboesa) utilizada na elaboração dos iogurtes foi de 1,25 g de ácido cítrico por $100 \mathrm{~g}$ de polpa. $\mathrm{O}$ pH médio foi de 3,45 e o teor de sólidos solúveis totais foi de $7,6{ }^{\circ}$ Brix. 
A composição físico-química (média) do iogurte probiótico de frutas vermelhas, com 1 dia de fabricação foi: extrato seco total de $17,67 \%$; gordura total de $0,22 \%$; proteína total de $3,51 \%$; cinzas de $1,05 \%$ e carboidratos totais de $12,90 \%$, com $\mathrm{pH}$ de 4,76 e acidez titulável de 0,81 g ácido láctico $\%$.

$\mathrm{O} \mathrm{pH}$ dos iogurtes elaborados foi superior ao normalmente verificado em iogurtes. Akalin et al. (2004) verificaram valores de $\mathrm{pH}$ inicial entre 4,51 e 4,48 para os diferentes iogurtes. Kailasapathy et al. (2008) 25 obtiveram valores médios de $\mathrm{pH}$ de 4,62 e 4,68 para iogurte natural e para iogurtes com frutas. Já Barbosa; Gallina (2017) elaboraram uma bebida com iogurte probiótico e polpa de manga, com $\mathrm{pH}$ em torno de 4,65 e 4,70 com 1 dia de fabricação, similar ao $\mathrm{pH}$ médio obtido para o iogurte probiótico elaborado.

Em relação à acidez titulável, Tarakçi; Kuçukoner (2003) obtiveram uma acidez titulável média para os iogurtes de 1,31g/100g. Enquanto Hernández-Herrero; Frutos (2014) obtiveram uma acidez inicial em torno de 0,85\% ácido láctico para iogurtes com polpa de ameixa. A baixa acidez favorece a aceitabilidade do produto pelos consumidores e ocasiona um menor decréscimo das células viáveis do microrganismo probiótico. Os iogurtes foram propositalmente elaborados com menor acidez, já que a fermentação foi interrompida em $\mathrm{pH}$ superior a 4,6 visando favorecer a viabilidade dos probióticos no produto, tendo em vista que o baixo $\mathrm{pH}$ e a pós acidificação afetam a viabilidade das bifidobactérias. Contudo, a acidez do iogurte probiótico elaborado está de acordo com a legislação vigente para iogurtes, que estabelece valores entre 0,6 a $1,5 \mathrm{~g}$ de ácido láctico/100g produto (BRASIL, 2007).

$\mathrm{O}$ teor de gordura médio obtido no iogurte probiótico, abaixo de $0,5 \mathrm{~g} / 100 \mathrm{~g}$ de produto pode caracterizá-lo como desnatado
(BRASIL, 2007). Isto se deve a utilização de leite desnatado para produção dos iogurtes, e também ao fato da polpa de frutas e demais ingredientes empregados não afetarem este parâmetro.

O teor médio de proteínas totais no iogurte probiótico foi de $3,51 \%$. Este valor é similar aos obtidos por Januário et al. (2017) para iogurtes aromatizados com sucos de vegetais orgânicos de beterraba com cenoura, mandioca, batata-doce ou suco de milho, que foram respectivamente de 3,3; 3,4; 3,5 e 3,8 g/100g. El Bakri; El Zubeir (2009) obtiveram valores médios de proteínas de 3,44 e $3,9 \%$ para iogurtes naturais e para iogurtes com frutas. A legislação brasileira prevê um valor mínimo de 2,9 g de proteína por $100 \mathrm{~g}$ de leite fermentado (BRASIL, 2007). Portanto, o iogurte probiótico está de acordo com a legislação e similar aos dados da literatura para iogurtes com frutas.

Januário et al. (2017) obtiveram teores de cinzas de 0,9 g/100 g para iogurtes aromatizados com sucos de vegetais orgânicos. O teor de cinzas médio do iogurte probiótico elaborado foi em torno de $1 \%$, similar ao observado por Tarakçi; Kuçukoner (2003) quando produziram iogurtes com frutas. Os teores de carboidratos totais estão dentro do esperado, considerando-se a adição de $10 \%$ de sacarose no produto final. A este valor deve-se considerar o teor de lactose remanescente no iogurte após a fermentação e o teor de carboidratos proveniente da polpa de frutas.

Observa-se que variações na composição de iogurte estão de acordo com a composição das frutas e vegetais empregados (JANUÁRIO et al., 2017).

\section{Qualidade microbiológica}

A quantificação de bolores e leveduras e coliformes são importantes parâmetros para a qualidade higiênico-sanitária de 
um produto. Os iogurtes foram avaliados após um dia de fabricação. As contagens de bolores e leveduras variaram de 1,0 a $3,0 \times 10^{1}$ UFC. $g^{-1}$, enquanto as contagens de coliformes à $30{ }^{\circ} \mathrm{C}$ e $45{ }^{\circ} \mathrm{C}$ foram $<0,3$ NMP.g ${ }^{-1}$, para os três processamentos.

A ANVISA define o limite quanto às contagens de coliformes a $45^{\circ} \mathrm{C}$, para leites fermentados, com ou sem adições, refrigerado, de, no máximo, 10 coliformes/g a $45^{\circ} \mathrm{C}$, na amostra indicativa (ANVISA, 2001). Já o MAPA (Ministério da Agricultura, Pecuária e Abastecimento), que regulamenta o padrão de identidade e qualidade para leites fermentados, indica que o produto deve apresentar, na amostra indicativa, o máximo de 10 coliformes $\left(30^{\circ} \mathrm{C}\right)$; índice $<3$ para coliformes totais $\left(45^{\circ} \mathrm{C}\right)$ e no máximo 50 UFC de bolores/leveduras por grama de produto (BRASIL, 2007). Portanto, os resultados obtidos atestam a boa qualidade microbiológica dos iogurtes probióticos elaborados, os cuidados na manipulação e no preparo das formulações e garantem a segurança para seu consumo.

\section{Avaliações físico-químicas durante a estocagem}

\section{pH e acidez titulável}

A acidez titulável é um importante indicador de qualidade em iogurtes e bebidas lácteas, e quando a acidez aumenta normalmente ocorre diminuição no $\mathrm{pH}$. $\mathrm{O}$ aumento da acidez ao longo da estocagem se justifica, pois mesmo sob refrigeração as bactérias continuam fermentando lentamente a lactose e produzindo ácido láctico, diminuindo o pH, e aumentando a acidez (BARBOSA; GALLINA, 2017; JANUÁRIO et al., 2017).

A acidez titulável média dos iogurtes foi de 0,8095 (1 dia) e 1,0061 g de ácido láctico/100 g de produto (30 dias). Os resultados para acidez titulável estão de acordo com aos valores estipulados pela legislação brasileira para iogurtes, entre 0,6 e 1,5 g de ácido lático por $100 \mathrm{~g}$ de produto (BRASIL, 2007). Verificou-se um aumento significativo da acidez $(\mathrm{P}<0,05)$ a partir de 10 dias de estocagem refrigerada. A pós-acidificação de iogurtes durante a estocagem refrigerada pode ser atribuída à produção de ácido lático, especialmente pelo L. bulgaricus (KAILASAPATHY et al., 2008; KORBEKANDI et al., 2015).

$\mathrm{O} \mathrm{pH}$ dos iogurtes foi de 4,77 (1 dia) e 4,63 (30 dias). Verificou-se que houve diferença significativa $(\mathrm{P}<0,05)$ no $\mathrm{pH}$ a partir de 20 dias de estocagem. Normalmente é observado um decréscimo no $\mathrm{pH}$ de produtos lácteos fermentados ao longo do tempo devido a produção de ácidos orgânicos pelas bactérias lácticas (GALLINA et al., 2012). Dentre as bactérias lácticas do iogurte, o L. delbrueckii ssp. bulgaricus é o principal responsável pela diminuição do $\mathrm{pH}$ durante a vida de prateleira (KAILASAPATHY et al., 2008). Akalin et al. (2004) avaliaram amostras de iogurte probiótico durante a estocagem e observaram que o $\mathrm{pH}$ de todas as amostras diminuiu ligeiramente durante o armazenamento a $4{ }^{\circ} \mathrm{C}$ por 28 dias, não sendo significativa essa alteração, com o pH final não ficando abaixo de 4,4, considerando que, devido ao pequeno abaixamento de $\mathrm{pH}$, é improvável que essas alterações afetem a viabilidade dos probióticos.

Outros trabalhos que estudaram a adição de polpa de fruta em iogurtes também verificaram aumento da acidez e redução do $\mathrm{pH}$ ao longo do armazenamento destes produtos (KAILASAPATHY et al., 2008; GALLINA et al., 2012; HOSSAIN et al., 2012). A importância do pH e acidez está relacionada com as suas características sensoriais, assim como, a viabilidade dos microrganismos presentes no produto.

Taxa de dessoragem (sinérese) 
O processo de dessoragem ou sinérese do iogurte é um atributo importante na aceitação do produto pelo consumidor. Este fenômeno se caracteriza pela liberação espontânea de água do gel, podendo ser intensificado por mudanças na temperatura, $\mathrm{pH}$ e por fatores mecânicos, como vibração (SILVA et al., 2010). A taxa de dessoragem ou sinérese (média) na superfície das amostras, foi de $0 ; 0,12 ; 0,24$ e $0,38 \mathrm{~cm}$, com 1,10 , 20 e 30 dias de armazenamento, respectivamente.

Após 1 dia de fabricação, o produto não apresentou dessoragem, resultado similar ao obtido por Silva et. al. (2010), que na elaboração de iogurte probiótico não observou dessoragem no tempo zero (início da estocagem). Verificou-se que houve diferença significativa $(\mathrm{P}<0,05)$ ao longo da estocagem do iogurte. A sinérese observada no iogurte pode ser proveniente da consistência e da acidez da polpa de frutas vermelhas empregada, e pelo próprio iogurte (LUCEY et al., 1997). Portanto, a aplicação de polpas na elaboração de iogurtes pode resultar em alterações na estrutura da rede proteica formada no produto, levando a sinérese do mesmo. Além disso, segundo Brandão (1995), valores de $\mathrm{pH}$ acima de 4,6 favorecem a dessoragem, pois o gel não fora suficientemente formado. No entanto, a taxa de sinérese, ao final dos 30 dias de estocagem, foi menor que os valores citados na literatura (SILVA et. al., 2010). Tendo em vista que a diminuição da sinérese tem um efeito desejável para obtenção de um iogurte mais estável e de maior aceitabilidade, os resultados obtidos podem ser considerados satisfatórios.

\section{Viabilidade da cultura probiótica}

A viabilidade de probióticos em iogurtes depende de uma série de fatores tais como, das bactérias probióticas incorporadas, culturas de iogurte utilizadas, interação entre as espécies presentes, condições da cultura, tempo de fermentação, condições de armazenamento, $\mathrm{pH}$ do iogurte (pós-acidificação durante o armazenamento), concentração de açúcar (pressão osmótica), teor de sólidos do leite, disponibilidade de nutrientes, presença de peróxido de hidrogênio, teor de oxigênio dissolvido (especialmente para Bifidobacterium spp.), capacidade tampão e concentração de $\beta$-galactosidase (KAILASAPATHY et al., 2008).

A viabilidade dos probióticos (bifidobactérias) se manteve em torno de $8 \mathrm{log}$ UFC.mL $L^{-1}$, variando de 8,$16 ; 8,12 ; 8,04$ e 7,97 $\log$ UFC.mL $\mathrm{mL}^{-1}$ após 1, 10, 20 e 30 dias de fabricação, respectivamente. Apesar deste decréscimo nas contagens ao longo da estocagem, esta diferença não foi significativa (P > 0,05). De acordo com o MAPA (BRASIL, 2007), quando se emprega bifidobactérias em iogurte ou leites fermentados, a contagem deverá ser de no mínimo $10^{6} \mathrm{UFC}_{\mathrm{g}}{ }^{-1}$. Contudo, diversos autores relatam a importância da sobrevivência das bactérias probióticas no produto alimentício, em populações suficientemente elevadas para ser de importância fisiológica ao consumidor, em torno de 6 a 7 log UFC/grama de produto (KUMAR; KUMAR, 2016).

Gallina et al. (2011) verificaram contagens de bifidobactérias de $6 \log \mathrm{UFC} / \mathrm{mL}$ para iogurte probiótico adicionado de FOS durante 28 dias de estocagem refrigerada. Gallina et al. (2012) observaram que a viabilidade da cultura probiótica em uma bebida desenvolvida com uma mistura (50/50\%) de leite fermentado (com cultura de iogurte e bifidobactérias) e polpa de goiaba, com e sem a adição de FOS, se manteve com valores entre $10^{6}$ e $10^{7} \mathrm{UFC} / \mathrm{mL}$, durante 30 dias de estocagem refrigerada. Akalin et al. (2004) obtiveram níveis de $10^{7} \mathrm{UFC} / \mathrm{g}$ em iogurte, quando empregou Bifidobacterium animalis, verificando ainda que não houve diferença significativa nas contagens até o final da estocagem, permanecendo dentro 
do limite recomendado de 1 milhão de células por grama de iogurte durante a estocagem. Vários autores propõem que a dose diária mínima da cultura probiótica considerada terapêutica seja de $10^{8}$ a $10^{9}$ UFC, o que corresponde ao consumo de $100 \mathrm{~g}$ de produto contendo $10^{6}$ a $10^{7} \mathrm{UFC} / \mathrm{g}$ (LOURENS-HATTINGH; VILJOEN, 2001; KAILASAPATHY et al. 2008; KAUR et al., 2014). Portanto, as contagens finais das bifidobactérias no iogurte probiótico com polpa de frutas vermelhas se mantiveram em níveis apropriados durante a estocagem para propiciar o efeito terapêutico, bem como para atender as exigências da legislação.

\section{Avaliação Sensorial - Teste de Aceitabilidade}

Um grupo de 60 consumidores de iogurte foram recrutados para avaliar a amostra de iogurte probiótico de frutas vermelhas, sendo 9 homens e 51 mulheres, com faixa etária variando entre 18 e 35 anos $(61,7 \%)$; $33,3 \%$ variando entre 36 e 55 anos e $5 \%$ acima dos 55 anos; sendo 3,3\% pertencente a classe social $\mathrm{A} 1,16,7 \%$ a $\mathrm{A} 2,35 \%$ a classe $\mathrm{B} 1,33,3 \%$ a $\mathrm{B} 2,10 \%$ a classe $\mathrm{C} 1$ e $1,7 \%$ a $\mathrm{C} 2$. Quanto à frequência de consumo de iogurte $13,3 \%$ relataram que consomem uma vez ao dia ou mais, $30 \%$ consomem até seis vezes por semana, $41,7 \%$ consomem pelo menos uma vez na semana, $6,7 \%$ consomem duas vezes ao mês e $8,3 \%$ que consomem uma vez ao mês.

Os resultados médios obtidos no teste de aceitabilidade de modo geral e em particular da aparência, da consistência e do sabor da amostra de iogurte de frutas vermelhas e por meio de escala do ideal quanto à cor, consistência, sabor de frutas vermelhas, acidez e doçura e quanto a intenção de compra, bem como, as porcentagens de "aceitação", "indiferença" e "rejeição", associadas às amostras por meio das escalas hedônicas utilizadas, correspondentes às porcentagens de valores da escala de 9 a 6 (aceitação), 5 (indiferença) e de 4 a 1 (rejeição), as porcentagens de "mais escura, mais consistente/ intensa", "ideal" e "mais clara, menos consistente/ intensa", correspondentes às porcentagens de valores da escala do ideal de 7 a 5 (acima do ponto médio), 4 (ponto médio) e de 3 a 1 (abaixo do ponto médio) e as porcentagens de intenção de compra de valores da escala 4 e 5 (positiva), 3 (neutra) e 2 e 1 (negativa), respectivamente, estão apresentados na Tabela 1 .

Quanto à aceitabilidade do produto de modo geral e em particular da aparência, sabor e consistência, verifica-se que a amostra obteve médias situadas entre "gostei muito" e "gostei". De acordo com Peuckert et al. (2010), um produto de boa aceitação, deve apresentar índice de aceitação igual ou superior a $70 \%$. Desta forma, pode-se inferir, que o iogurte probiótico sabor frutas vermelhas, cuja aceitação apresentou índices variando entre $78 \%$ e $90 \%$ apresentou elevada aceitação pelos consumidores (Tabela 1).

Em relação aos atributos avaliados com a escala do ideal, a cor do produto e a acidez obtiveram médias próximas ao ideal. As médias quanto ao sabor de frutas vermelhas, à doçura e à consistência situaram-se entre "um pouco menos intenso/ um pouco menos doce/ um pouco menos consistente do que eu gosto" e "do jeito que eu gosto". $40 \%$ dos consumidores julgaram que a cor da amostra é mais clara do que o ideal, $30 \%$ julgou que a cor é ideal e $30 \%$ julgou que a cor é mais escura do que o ideal. Mais de $20 \%$ dos consumidores julgaram a amostra com acidez mais intensa, sabor de frutas menos intenso, menos doce e menos consistente do que o ideal, sendo que para os atributos acidez e doçura mais de $65 \%$ dos consumidores julgaram que a intensidade estava ideal. Em relação à intenção de compra, mais de $50 \%$ dos consumidores indicaram intenção de compra positiva. 
Tabela 1 - Resultados da avaliação da aceitabilidade de modo geral, aparência, sabor e da consistência da amostra de iogurte probiótico de frutas vermelhas e quanto à cor, sabor de frutas vermelhas, acidez, doçura, consistência ideal

\begin{tabular}{|c|c|c|c|c|c|}
\hline Atributos & & Aceitabilidade* & Aceitação (\%) & Indiferença $(\%)$ & Rejeição (\%) \\
\hline \multirow{4}{*}{ Hedônica } & Modo geral & $6,8(1,4)$ & 86,6 & 3,3 & 10,0 \\
\hline & Aparência & $6,7(1,2)$ & 90,0 & 0,0 & 10,0 \\
\hline & Sabor & $6,5(1,6)$ & 78,3 & 3,3 & 18,4 \\
\hline & Consistência & $6,5(1,4)$ & 78,0 & 6,7 & 15,0 \\
\hline \multirow{6}{*}{ Ideal } & & & $\begin{array}{c}\text { mais clara, } \\
\text { menos } \\
\text { consistente/ } \\
\text { intensa }(\%)\end{array}$ & Ideal $(\%)$ & $\begin{array}{c}\text { mais escura, } \\
\text { mais } \\
\text { consistente/ } \\
\text { intensa }(\%)\end{array}$ \\
\hline & Cor & $3,9(1,0)$ & 40,0 & 30,0 & 30,0 \\
\hline & $\begin{array}{l}\text { Sabor de frutas } \\
\text { vermelhas }\end{array}$ & $3,7(0,8)$ & 30,0 & 55,0 & 15,0 \\
\hline & Acidez & $4,2(0,7)$ & 3,3 & 75,0 & 21,6 \\
\hline & Doçura & $3,7(0,6)$ & 26,6 & 66,7 & 6,7 \\
\hline & Consistência & $3,5(0,7)$ & 43,3 & 51,7 & 5,0 \\
\hline \multirow{2}{*}{\multicolumn{2}{|c|}{ Intenção de compra }} & & Negativa (\%) & Neutra (\%) & Positiva (\%) \\
\hline & & $3,6(1,1)$ & 15,0 & 31,7 & 53,3 \\
\hline
\end{tabular}

*Resultado expresso como média (desvio padrão) entre 60 avaliações.

\section{CONCLUSÕES}

O iogurte probiótico apresentou qualidade higiênico-sanitária apropriada e composição (média) de: 17,67\% de extrato seco total; $0,22 \%$ de lipídios; $3,51 \%$ de proteínas; $1,05 \%$ de cinzas e $12,90 \%$ de carboidratos totais, sendo uma matriz favorável para a manutenção das bifidobactérias que mantiveram-se em torno de $8 \log$ UFC.mL $\mathrm{m}^{-1}$ durante 30 dias de estocagem refrigerada. O produto obteve mais de $75 \%$ de aceitação para os atributos avaliados, destacando-se a aparência, o sabor e a consistência com médias entre "gostei muito" e "gostei", sendo que $53,3 \%$ dos consumidores demonstraram atitude positiva quanto à intenção de compra.

\section{REFERÊNCIAS}

ABEP. Associação Brasileira de Empresas de Pesquisa. Critério de Classificação Econômica Brasil, CCEB 2014 - Base LSE 2012. Disponível em <http://www.abep.org/ Servicos/Download.aspx?id=01> Acesso em: 02 de julho 2014.

AKALIN, A. S.; FENDERYA, S.; AKBULUT, $N$. Viability and activity of bifidobacteria in yoghurt containing fructooligosaccharide during refrigerated storage. International Journal of Food Science and Technology, v. 39, p. 613-621, 2004.

AGÊNCIA NACIONAL DE VIGILÂNCIA SANITÁRIA (ANVISA). Resolução RDC nº 12 
de 02 de Janeiro de 2001. Aprova o Regulamento sobre Padrões Microbiológicos para Alimentos. Diário Oficial da República Federativa do Brasil, Brasília, 10 jan. 2001.

ALMEIDA. M. H. B. et al. Potentially probiotic açaí yoghurt. International Journal of Dairy Technology, v. 61, n. 2, p. 178-182, 2008.

BARBOSA, P. P. M.; GALLINA, D. A.

Viabilidade de bactérias (starter e probióticas) em bebidas elaboradas com iogurte e polpa de manga. Revista do Instituto de Laticínios Cândido Tostes, v. 72, n. 2, p. 85-95, 2017.

BRANDÃO, S. C. C. Tecnologia da produção industrial de iogurte. Leite e Derivados, v. 5, n. 25, p. 24-38, 1995.

BRASIL. Ministério da Agricultura, Pecuária e Abastecimento. Secretaria da Defesa Agropecuária. Laboratório Nacional de Referência Animal. Instrução Normativa $n^{\circ} 68$ de 12 de dezembro de 2006. Métodos analí- ticos oficiais físico-químicos para controle de leite e produtos lácteos. V - Métodos quantitativos. Diário Oficial da República Federativa do Brasil, Brasília, dez. 2006.

BRASIL. Ministério da Agricultura, Pecuária e Abastecimento. Instrução Normativa $n^{\circ}$ 46, de 23 de outubro de 2007. Adota o Regulamento Técnico de Identidade e Qualidade de Leites Fermentados. Diário Oficial da República Federativa do Brasil, Brasília, 24 out. 2007.

EL BAKRI, J. M.; EL ZUBEIR, I. E. M.

Chemical and microbiological evaluation of plain and fruit yoghurt in Khartoum State, Sudan. International of Dairy Science, v. 4, n. 1, p. 1-7, 2009.

FARNWORTH, E. R. et al. Growth of probiotic bacteria and bifidobacteria in a soy yogurt formulation. International Journal of Food Microbiology, v. 116, n.1, p. 174- 181, 2007.

FOOD AND AGRICULTURE ORGANIZATION OF THE UNITED NATIONS AND WORLD HEALTH ORGANIZATION REPORT (FAO/WHO). Report of a joint FAO/WHO evaluation of health and nutritional properties of probiotics in food including powder milk and live lactic acid bacteria. Córdoba, Argentina, 2001, 34 p. Disponível em: <ftp://ftp.fao.org/es/esn/ food/probio_report_en.pdf $>$. Acesso em: 20 mar. 2017.

FRANK, J. F.; YOUSEF, A. E. Tests for groups of microorganisms. In: WEHR, H. M.; FRANK, J. F. (Ed.). Standard Methods for the examination of dairy products (17th ed.). American Public Health Association, Washington, D.C., 2004. p. 227-247.

GALLINA, D. A. et al. Caracterização de leites fermentados com e sem adição de probióticos e prebióticos e avaliação da viabilidade de bactérias láticas e probióticas durante a vidade-prateleira. Unopar Ciências Biológicas e da Saúde, v. 13, n. 4, p. 239-244, 2011.

GALLINA, D. A. et al. Caracterização de bebida obtida a partir de leite fermentado simbiótico adicionado de polpa de goiaba e avaliação da viabilidade das bifidobactérias. Revista do Instituto de Laticínios Cândido Tostes, v. 67, n. 386, p. 45-54, 2012.

GONZALEZ, N. J.; ADHIKARI, K.; SANCHO-MADRIZ, M. F. Sensory characteristics of peach-flavored yogurt drinks containing prebiotics and synbiotics. LWT - Food Science and Technology, v. 44, p. 158-163, 2011. 
GRANATO, D. et al. Probiotic dairy products as functional foods. Comprehensive reviews in food science and food safety, v. 9, n. 5, p. $455-470,2010$.

HERNÁNDEZ-HERRERO, J. A.; FRUTOS, M. J. Effect of concentrated plum juice on physicochemical and sensory properties of yoghurt made at bench top scale. International Journal of Dairy Technology, v. 67, n. 1, 2014.

HORWITZ, W., ed. Official Methods of Analysis of AOAC International. 17th Ed., 2000, Vol. II. Food Composition; Additives; Natural Contaminants, chap 33, p. 10; 54; 61; 71. (Proc. 920.108; 930.30; 935.42 and 945.46).

HOSSAIN, M. N. et al. Quality comparison and acceptability of yoghurt with different fruit juices. Jounal of Food Processing Technology, v. 3, n. 8:171, p. 1-5, 2012.

\section{INTERNATIONAL DAIRY FEDERATION} (IDF). Determination of the total nitrogen content of milk by Kjeldahl method. Brussels: FIL/IDF, 1993. 11p.

\section{INTERNATIONAL DAIRY FEDERATION} (IDF). Bulletin of the IDF $\mathbf{N}^{\mathbf{4}} \mathbf{4 1 1 / 2 0 0 7}$. Selective enumeration of bifidobacteria in dairy products: development of a standard method, 20 p., 2007.

INSTITUTO ADOLFO LUTZ ( IAL). Leites e Fermentados - Determinação da acidez em ácido láctico. In: Métodos físico-químicos para análise de alimentos. Ed. 4, São Paulo: Instituto Adolfo Lutz. Cap. 27, p. 879, 2008.

INTERNATIONAL ORGANIZATION FOR STANDARDIZATION (ISO). ISO 4831: Microbiology of food and animal feeding stuffs - Horizontal method for the detection and enumeration of coliforms - Most probable number technique. 3rd ed., 2006.

INTERNATIONAL ORGANIZATION FOR STANDARDIZATION (ISO). ISO 7251:

Microbiology of food and animal stuffs. Horizontal method for the detection and enumeration of presumptive Escherichia coli Most probable number technique. 3rd ed., 2005.

JANUÁRIO, J. G. B. et al. Probiotic yoghurt flavored with organic beet with carrot, cassava, sweet potato or corn juice: Physicochemical and texture evaluation, probiotic viability and acceptance. International Food Research Journal, v. 24, n. 1, p. 359-366, 2017.

KAILASAPATHY, K.; HARMSTORF, I.; PHILLIPS, M. Survival of Lactobacillus acidophilus and Bifidobacterium animalis ssp. lactis in stirred fruit yogurts. Food Science and Technology, v. 41, n. 7, p. 1317-1322, 2008.

KAUR, A. et al. Probiotics and its health benefits. Journal of Global Biosciences, v. 3, n. 3, p. 686-693, 2014.

KORBEKANDI, $H$. et al. Evaluation of probiotic yoghurt produced by Lactobacillus paracasei ssp. tolerans. Journal of Food Biosciences and Technology, v. 5, n. 1, p. 3744, 2015.

KUMAR, A.; KUMAR, D. Development of antioxidant rich fruit supplemented probiotic yogurts using free and microencapsulated Lactobacillus. Jounal of Food Science and Technology, v. 53, n. 1, p. 667-675, 2016.

LOURENS-HATTINGH, A.; VILJOEN, B. C. Yogurt as probiotic carrier food. International Dairy Journal, v. 11, p. 1-17, 2001. 
LUCEY, J. A. et al. Properties of acid ca- sein gels made by acidification with glu- conodlactone. I. Rheological properties. International Dairy Journal, v. 7, pp. 381388, 1997.

MACBEAN, R. D. Chapter 8. Packaging and the Shelf Life of Yogurt. In: GORDON L. ROBERTSON. Food Packaging and Shelf Life. A Practical Guide. Boca Raton: CRC Press, 2010. 143-156.

MEILGAARD, M.; CIVILLE, G. V.; CARR, B.T. Sensory evaluation techniques. $4^{\mathrm{a}} \mathrm{ed}$. Boca Raton: CRC Press, 2006. 448 p.

MELO, E. A.; MACIEL, M. I. S.; LIMA, V. L. A. G.; NASCIMENTO, R. J. Capacidade antioxidante de frutas. Revista Brasileira de Ciências Farmacêuticas, v. 44, n. 2, p. 193201, 2008.

OLIVEIRA, D. et al. Sensory, microbiological and physicochemical screening of probiotic cultures for the development of non-fermented probiotic milk. LWT - Food Science and Technology, v. 79, p. 234-241. 2017.

PEUCKERT, Y. P. et al. Caracterização e aceitabilidade de barras de cereais adicionados de proteína texturizada de soja e camucamu (Myrciaria dúbia). Revista Alimentos e Nutrição, v. 21, n. 1, p. 147-152, 2010.

SILVA, M. E. C.; PACHECO, M. T. B.; ANTUNES, A. E. C. Estudo da viabilidade tecnológica da aplicação de coacervado de proteínas de soro de leite com carboximetil celulose em iogurte probiótico. Brazilian Journal of Food and Technology, v. 13, n. 1, p. 30-37, 2010.

TARAKÇI, Z.; KÜÇÜKÖNER, E. Physical, chemical, microbiological and sensory characteristics of some fruit-flavored yoghurt. YYÜ Vet Fak Derg, v. 14, n. 2, p. 10-14, 2003. 